\title{
A IMUNIDADE TRIBUTÁRIA AOS CULTOS E A LIBERDADE DE CRENÇA EM UM ESTADO LAICO
}

\author{
Fabiane Simioni $^{1}$
}

1 APONTAMENTOS TEÓRICOS SOBRE IMUNIDADE TRIBUTÁRIA

Creio que a essência do fanatismo reside no desejo de forçar as outras pessoas a mudarem. [...] O fanático é uma criatura bastante generosa. É um grande altruísta. Frequentemente, o fanático está mais interessado em você do que nele próprio. Ele quer salvar sua alma, quer redimi-lo, quer libertálo do pecado, do erro, do fumo, de sua fé ou de sua falta de fé, quer melhorar seus hábitos alimentares ou curá-lo de seus hábitos de bebida ou de voto. O fanático importa-se muito com você, ele está sempre ou se atirando no seu pescoço, porque o ama de verdade, ou apertando sua garganta, caso você prove ser irrecuperável. E, de qualquer modo, falando topograficamente, atirar-se no pescoço de alguém ou apertar sua garganta é quase o mesmo gesto. (OZ, Amós. Como curar um fanático. Rio de Janeiro: Ediouro, 2004.)

Se o fanatismo é considerado generoso e altruísta por $\mathrm{Oz}$ (2004), não muito distante está a política fiscal brasileira quando se trata das imunidades tributárias relativas aos cultos e templos religiosos, chancelada pela atual jurisprudência do Supremo Tribunal Federal.

De acordo com Martins (1993, p. 39), a imunidade tributária tem por objetivo impedir que os poderes tri-

1 Doutoranda em Direito (UFRGS/CAPES), membro da Red Iberoamericana por las Libertades Laicas. 
butantes, pressionados por seus déficits orçamentários e a busca incansável por receita, invadam áreas que no interesse da sociedade devam ser preservadas e mantidas.

Nesse sentido é que a Constituição Federal de 1988 impede a arrecadação de tributos sobre templos de qualquer culto; patrimônio, renda ou serviços dos partidos políticos, inclusive suas fundações, das entidades sindicais dos trabalhadores, das instituições de educação e de assistência social, sem fins lucrativos, atendidos os requisitos da Lei; livros, jornais, periódicos e o papel destinado a sua impressão.

A proposta deste ensaio é analisar a imunidade tributária conferida aos templos de qualquer culto. Para tanto, discute-se a imunidade conferida no artigo 150, inciso VI, alínea "b" da Constituição Federal de 1988, a partir da afirmação do Estado brasileiro enquanto um Estado laico. Nesse sentido, propõe-se a seguinte questão norteadora: a imunidade atribuída aos templos, na contemporaneidade brasileira, se presta à finalidade de garantia do respeito à liberdade de crença e de culto, ou seja, da liberdade religiosa?

$O$ disposto na alínea "b" do inciso VI do artigo 150 da Constituição Federal veda a instituição de imposto sobre "templos de qualquer culto". O templo é o local onde são prestados cultos religiosos. Em princípio, o templo compreenderia o imóvel dedi- cado ao culto (o terreno e o prédio), e a vedação de arrecadação tributária abrangeria apenas os impostos incidentes sobre imóveis.

No entanto, o parágrafo $4^{\circ}$ do artigo 150 da Constituição, ao determinar que o disposto nas alíneas "b" e "c" do inciso VI "compreendem somente o patrimônio, a renda e os serviços relacionados com as finalidades essenciais das entidades nelas mencionadas", permite uma interpretação mais extensa do conteúdo da imunidade, de forma a abranger a "renda do templo", o "patrimônio do templo" e os "serviços do templo", de acordo com Marton (2004).

Se o templo não tem personalidade jurídica e o imóvel destinado aos cultos religiosos pertence a uma organização religiosa, tal organização não pode sofrer a incidência de impostos que vise a tributar o imóvel em questão, ou a renda auferida em decorrência do culto ou que se destine ao culto, ou os serviços integrantes da atividade religiosa em si mesma considerada.

$\mathrm{O}$ dispositivo do parágrafo $7^{\circ}$ do artigo 195 da Constituição não se refere a templos, nem a organizações religiosas. Com efeito, o mencionado dispositivo dispõe que: "São isentas de contribuição para a seguridade social as entidades beneficentes de assistência social que atendam às exigências estabelecidas em lei".

Observa-se, primeiramente, que a imunidade do inciso VI do artigo 150 
refere-se a imposto, enquanto o $\S 7^{\circ}$ do artigo 195 diz respeito a "contribuição para a seguridade social”. Em segundo lugar, o disposto no mencionado $\S 7^{\circ}$ aplica-se a "entidades beneficentes de assistência social que atendam às exigências estabelecidas em lei", não havendo qualquer menção a "templos de qualquer culto". Portanto, nenhuma relação existe entre os dois dispositivos citados.

A imunidade conferida aos templos não se funda, portanto, no caráter assistencialista ou assistencial de algumas das práticas que compõem o repertório das organizações religiosas, como querem crer alguns autores.

Assim, temos que o alcance da imunidade estaria limitada (i) aos imóveis que guarnecem as entidades religiosas nas suas práticas de culto; (ii) a renda auferida em decorrência do culto ou que se destine ao culto; (iii) aos serviços integrantes da atividade religiosa em si mesma considerada.

Entretanto, atualmente, no Brasil, há uma diversidade de práticas religiosas que se desenvolvem dentro e fora dos templos.

\section{PRÁTICAS RELIGIOSAS: $O$ CULTO E O TEMPLO}

As formas de religiosidade são muito distintas entre si, embora seja possível encontrar semelhanças e pontos de contato em pelo menos muitas delas: a referência ao transcendente, ao sobrenatural, ao absoluto. Por força dessa sua natureza, ela é capaz de liberar energias incontroláveis, surgindo, historicamente, ligada ao que existe de melhor e de pior na história da humanidade.

Essa abertura ao transcendente está longe de traduzir a ideia de liberdade religiosa.

Assim, temos o que se poderia categorizar como uma história da ideia de liberdade religiosa:

1. No Cristianismo, com a máxima "à Cesar o que é de Cesar, à Deus o que é de Deus", temos a afirmação dos direitos da Igreja em relação ao Estado (momento hierocrático).

2. Afirmação dos direitos do Estado sobre a Igreja (momento regalista).

3. Afirmação dos direitos dos cidadãos relativamente ao Estado e à Igreja (momento constitucional).

A análise das imunidades tributárias relativas aos templos de qualquer culto religioso tem como pressuposto jurídico-constitucional a necessidade de respeito aos valores constitucionais da igual dignidade e igual liberdade de todo/toda o/a cidadão/cidadã.

Para tanto, apoiamo-nos no postulado da razão pública, nos termos pro- 
postos por Rawls e Habermas, a fim de demonstrar que:

1. a imunidade tributária de templos de quaisquer cultos e religiões se expressa como uma prática cultural brasileira que abrange um complexo de atividades instrumentais, não caracteristicamente religiosas, mais ou menos próximas da atuação religiosa;

2. as pretensões das confissões religiosas se encontram limitadas pelo direito de autonomia religiosa individual, ou liberdade de crença.

A razão pública rawlsiana é sustentada pela cultura política, ideias e princípios fundamentais, compartilhados por uma sociedade democrática. Para Habermas (2003), desde a perspectiva da teoria do agir comunicativo, o consenso racional repousa sobre o reconhecimento intersubjetivo de pretensões validamente criticáveis.

Convém destacar, desde logo, que não se pretende fazer uma crítica às posições doutrinárias das diferentes concepções religiosas. Entretanto, é necessário trazer ao debate os usos da doutrina religiosa, na construção de argumentos jurídicos em sociedades nas quais essa doutrina goza de prestígio e privilégio.

Seguindo na linha de Sabbag (2009), o culto é a manifestação de uma prática religiosa. Essa manifesta- ção pode ser do âmbito privado, mas também pode ser coletiva, na medida em que um grupo de indivíduos que compartilhem as mesmas práticas e crenças religiosas, se reúnem em local público, o templo. Na acepção moderna, o templo se constitui das coisas e das pessoas que se organizam para a manutenção de um culto e das práticas religiosas compartilhadas.

O conceito de templo terá, portanto, fundamental importância para a interpretação das imunidades tributárias. Desta forma, caberá ao julgador, no caso concreto, verificar o que é passível de imunidade, de acordo com os fins postulados pela Constituição Federal, e assim concretizar a justiça fiscal aos templos de qualquer culto.

\section{FUNDAMENTOS HISTÓRICOS DA LIBERTAS RELIGIONIS}

No Império Romano, todos os cultos eram tolerados, desde que o cidadão romano aceitasse o culto ao Imperador. Os primeiros cristãos que se recusavam a oferecer sacrifícios pagãos eram condenados à morte. Nesse contexto, autores cristãos começam a falar de libertas religionis: havia a necessidade de respeito por um perímetro de privacidade individual, dentro do qual a opção de fé deveria permanecer inatacável (Machado, 1996).

A partir do século VI são editadas leis de tolerância, reconhecendo 
o direito de existência de templos e autorizando sua reconstrução. Constantino, em 312 d.C. se converte ao cristianismo e coloca o seu poder a serviço de sua nova fé. A partir de então, os éditos consagram o princípio da liberdade religiosa, nas suas dimensões de liberdade de crença e de culto (Machado, 1996).

O Cristianismo se torna a religio ufficiale, com Teodósio, em 380 d.C., cujo propósito era assegurar a paz terrena, a legitimidade do poder temporal, a estabilidade das instituições, a integração e a coesão do tecido social. As funções públicas, portanto, são cada vez mais confundidas com as religiosas, num verdadeiro processo de "cristianização do império" (Machado, 1996).

Os cristãos passaram de perseguidos para uma posição política e jurídica privilegiada. Os membros do clero cristão passam a beneficiar-se de uma proteção jurídica especial e de imunidades fiscais e jurisdicionais. Os não-cristãos, pagãos e hereges são alvo de intolerância formal, no plano jurídico, pela utilização de instrumentos públicos de coação e exclusão. É ordenada a destruição de todos os templos de culto pagão, bem como são confiscados seus bens (Machado, 1996).

Tem início a tradição de proteção à igreja cristã às custas do sacrifício da liberdade das outras crenças.

No Estado absolutista, o rei era a representação de todo poder esta- tal, sendo que ele concedia benesses a algumas classes em razão de seus interesses. Assim era na França, até o século XVIII, onde se tributavam apenas o Terceiro Estado, isto é, a burguesia, o proletariado e os camponeses enquanto a nobreza e o clero, representantes do Primeiro e Segundo Estados respectivamente, quase não eram tributados.

Nesse tipo de Estado a imunidade "significava um autêntico privilégio dos nobres e da Igreja frente ao poder do Rei”. A luta pela manutenção ou extinção desses privilégios foi um "fator que contribuiu para a deflagração da Revolução Francesa". Com ela instala-se o Estado de Direito, que tem como principal característica a primazia da lei, que serve como instrumento de proteção do cidadão contra o próprio Estado.

Os revolucionários franceses aboliram regalias do clero e da nobreza. Isso não quer dizer que todos os cidadãos franceses passaram a ter direitos iguais, já que a Revolução acabou por privilegiar os setores mais ricos da burguesia.

$\mathrm{O}$ direito de liberdade religiosa integra, para fins históricos, o catálogo dos direitos de primeira dimensão: das liberdades e garantias.

Já na Declaração Universal dos Direitos do Homem, de 1948, em seu artigo 18 assim proclama: "Todo homem tem o direito à liberdade de pensamento, consciência e religião; 
este direito inclui a liberdade de mudar de religião ou crença e a liberdade de manifestar essa religião ou crença, pelo ensino, pela prática, pelo culto e pela observância isolada ou coletivamente, em público ou em particular".

$\mathrm{O}$ direito à liberdade religiosa pretende, fundamentalmente, recortar em torno dos indivíduos e de grupos um perímetro de liberdade de opção e atuação religiosa que o Estado não pode vulnerar. Como corolários do direito à liberdade religiosa temos o direito subjetivo de defesa e normas de competência negativa (Machado, 1996, p. 198-9).

Com as revoluções do século XVIII consolida-se o Estado Fiscal, configuração específica do Estado de Direito, e o conceito de imunidade tributária se transforma radicalmente. Deixa de ser forma de limitação do poder do Rei pela Igreja e pela nobreza para se transformar em limitação do poder tributário do Estado pelos direitos preexistentes do indivíduo.

Em tempos de laicidade e de acepção moderna de imunidade tributária como um direito subjetivo do contribuinte imune de não pagar tributos, não se fala mais em privilégio, mas em um instituto que "preexistindo ao poder tributário como qualidade essencial da pessoa humana e correspondendo ao direito público subjetivo que erige a pretensão à incolumidade diante da ordem tributária objetiva" (Costa, 2006, p. 27).
$\mathrm{Na}$ teoria, laicidade é o regime social de convivência, na qual as instâncias políticas são legitimadas pela soberania popular e não mais pelas instituições religiosas. Nesse sentido, a governança política não adere a nenhuma opção filosófica ou religiosa, ela não exige de ninguém tal adesão como condição para a associação política. A laicidade se realiza onde a diversidade de crenças e de pertencimentos podem se exprimir e, idealmente, se harmonizar. (Lorea, 2008). Na mesma linha de raciocínio, Blancarte (2008) afirma que os defensores de um Estado laico tem a tarefa constante de relembrar a legisladores e funcionários públicos que suas funções devem ser exercidas de acordo com o interesse público, definido pela vontade popular da maioria, sem, todavia, excluir os direitos das minorias.

Nesse sentido, Tepedino (1994, p. 12) afirma que, ao conceder uma imunidade, a Constituição não está concedendo um benefício, mas tutelando um valor jurídico tido como fundamental para o Estado. Daí porque a interpretação das alíneas do artigo 150, inciso VI, da Constituição Federal de 1988 deve ser ampla e teleológica, nunca restritiva e literal.

Dessa forma, a tutela constitucional do valor liberdade de crença deve estar em harmonia com os demais valores, sobretudo quanto à igual dignidade e igual liberdade de todo/toda cidadão/cidadã. 


\section{ATIVIDADES COM FINS ECONÔMICOS E LIVRE CONCORRÊNCIA}

Desde a criação das igrejas primitivas, sabe-se que todas necessitam de recursos financeiros para a manutenção de suas práticas e para a missão de evangelização ou conversão de outros indivíduos que não compartilham das mesmas crenças.

Portanto, é consequência desses propósitos, o desenvolvimento de atividades econômicas para que os cultos organizados em templos promovam suas práticas e sua religiosidade.

Se, no início, a Igreja Católica vendia um pequeno pedaço do céu aos seus fiéis na promessa da vida eterna, hoje, quaisquer igrejas contam com um arsenal de artefatos comercializáveis: de livros, santos e velas a CD's, DVD's, e merchandising em programas de rádio e televisão. São atividades com fins lucrativos, as quais recairá a incidência tributária, quando as mesmas estão longe da finalidade essencial dos cultos.

Concordamos com Sabbag (2009), quando o autor refere que diante da evidência de prejuízo à livre concorrência na atividade econômica desenvolvida pelos templos e cultos, é necessário investigar sobre a abrangência da imunidade tributária em uma situação como essa.

De outra forma, não seria possível impedir ou vedar a prática de tais ati- vidades econômicas. Porém, estas devem respeitar o princípio da proporcionalidade e razoabilidade, de forma que não causem prejuízo ao princípio da concorrência, e que os recursos obtidos sejam totalmente aplicados para suas atividades essenciais.

A atividade comercial (com fins econômicos) dos templos, não pode violar o princípio concorrencial, prejudicando os demais empresários que não podem se valer da imunidade tributária, causando, deste modo, uma afronta ao princípio da igualdade.

$\mathrm{O}$ atual entendimento do Supremo Tribunal Federal é no sentido de que à exceção dos templos em que são realizadas as celebrações religiosas e das dependências que servem diretamente a estes fins, é legítima a cobrança de IPTU relativamente a lotes vagos e prédios comerciais de entidades religiosas (RE 325.822-SP).

Tal interpretação tem se consolidado no campo jurisprudencial. Mas nem sempre foi assim. As diversas constituições que o Brasil teve demonstram uma ambivalência no tratamento da questão.

\section{FUNDAMENTOS \\ CONSTITUCIONAIS DA IMUNIDADE AOS CULTOS E TEMPLOS RELIGIOSOS}

A Constituição do Império de 1824 declarou abertamente que a reli- 
gião oficial era a Católica Apostólica Romana, sem fazer qualquer referência à imunidade tributária:

Art. $5^{\circ}$. A religião Católica Apostólica Romana continuará a ser a religião do Império. Todas as outras religiões serão permitidas com seu culto doméstico ou particular, em casas para isso destinadas, sem forma alguma exterior de templo.

A Constituição Política do Império do Brasil, portanto, fundou um Estado confessional brasileiro que duraria mais de sessenta anos. Sob o aspecto da estrutura fiscal, é possível vislumbrar, quanto às imunidades tributárias, uma transferência da aplicação das regras jurídicas então em vigor em Portugal. Quanto aos tributos e suas isenções e imunidades, existia também uma pensão concedida para a capela imperial pelo Alvará de 20 de agosto de 1808 , que na verdade era um estímulo em dinheiro concedido pelo Estado para instituições católicas (Balthazar, 2005, p. 72).

No período da Regência (com a abdicação de Dom Pedro I em 7 de abril de 1831 até 1840, quando, então, Dom Pedro II é entronado) houve certo avanço, pois se implementou uma sistematização de impostos e uma descentralização por meio de discriminação de receitas tocantes às Províncias e de outras atinentes ao Governo Geral. Foi, também, durante esse período, que se estabeleceram algumas isenções fiscais. Contudo, as situações de imunidade de templos de qualquer culto restaram intocadas, permanecendo como direito/privilégio, ainda que não escrito (Balthazar, 2005, p. 89).

A Constituição de 1891, fortemente influenciada pela ideia republicana e pelo liberalismo em nova vertente, estabeleceu uma ruptura com a Igreja Católica como religião oficial. Esse rompimento está expressado em diversos dispositivos do texto constitucional:

Artigo 11 - Todos os indivíduos e todas as confissões religiosas podem exercer pública e livremente o seu culto, associando-se para esse fim e adquirindo bens, observadas as disposições do direito comum.

No parágrafo $7^{\circ}$ do artigo 172 , afirmou que nenhum culto ou igreja gozará de subvenção oficial, nem terá relações de dependência ou aliança com o Governo da União ou dos Estados.

Os ministros de confissão religiosa eram excluídos dos direitos políticos de votar e ser votado, fato que não se verificou no tempo do Império.

Também neste diploma não há qualquer referência à imunidade para os templos de qualquer culto.

Em um contexto de crise econômica e política interna, seguida da crise da Bolsa de Nova Iorque, em 1929, o Brasil promulga a Constituição de 
1934. Com a Revolução de 1930 , o governo de Getúlio tenta implementar um Estado do bem-estar social no Brasil. Para tanto, promulga a Constituição de 1934, inspirada na Constituição de Weimar de 1919, forjada entre o compromisso com o liberalismo e o intervencionismo.

$\mathrm{O}$ ensino religioso voltou às escolas públicas marcado pela facultatividade de frequência e pela liberdade de confissão (artigo 153). As escolas particulares foram beneficiadas pela "isenção de qualquer tributo", nos termos do artigo 154.

A constituição de 1934 reitera a vedação ao embaraço de cultos, conforme artigo 17, inciso II.

Com a Constituição de 1937 foi implantado o "Estado Novo", que rompeu com o regime democrático e com as liberdades individuais, por ter sido outorgada sob o argumento de proteção da democracia contra os partidos comunista e fascista que ofereciam perigo ao regime político da época. Novamente com a denominação "Constituição dos Estados Unidos do Brasil" ficou conhecida como "Polaca", e apenas restringe-se a repetir as disposições atinentes às "vedações" contidas na Constituição anterior, sem alterações substanciais no tocante às imunidades tributárias (Balthazar, 2005, p. 139).

Todo o arcabouço tributário contido nessa Constituição, bem como seu sistema de imunidades tributá- rias, teve fim no ano de 1945, com o advento de uma nova Constituição democrática. Nesse ano terminou, também, o segundo conflito bélico envolvendo os países mais poderosos em termos econômicos, bélicos, políticos e culturais, tendo saído vencedor o bloco dito defensor da liberdade e da democracia: os "Aliados". Ocorre que no Brasil da época, o ditador do "Estado Novo" negociava tanto com os nazistas como com os aliados no período anterior e, até mesmo durante o conflito. Desse modo, Vargas não se sustentou no poder, uma vez que seu governo ditatorial, e com um viés fascista, causava constrangimento político e alguma contradição naqueles que o deveriam apoiar interna e externamente. Por isso é que houve uma iniciativa do próprio governo, tendente a uma democratização por meio de uma nova Constituição: a Constituição dos Estados Unidos do Brasil de 18 de setembro de 1946 (Daneli Filho; Pilan Sobrinho, 2010).

Operou-se, por meio da promulgação desta constituição, um processo de redemocratização das instituições brasileiras que teve seu final com o Golpe Militar de 1964.

No que diz respeito às limitações ao poder de tributar, na Constituição de 1946 ocorreu um alargamento do número de casos beneficiados pela imunidade tributária. Nessa constituição, as imunidades dos templos de qualquer culto, bens e serviços dos 
partidos políticos, das instituições de educação e de assistência social, se fizeram presentes expressamente. Da mesma forma as imunidades recíprocas e sobre o papel destinado a impressão de livros, jornais e periódicos (Baleeiro et al., 1987, p. 143).

Com a implantação de um Regime Militar por meio de um golpe de Estado no ano de 1964, encerrando o período democrático iniciado com a Constituição de 1946, temos a Reforma Tributária de 1965 e o advento de um Código Tributário Nacional (CTN) em 1966, por meio da Lei n. 5.172 de 25 de outubro de 1966, tendo recebido a denominação apontada somente em 14 de março de 1967, com o Ato Complementar n. 36.

A Constituição de 1967 praticamente manteve as mesmas imunidades da constituição anterior. Sob o aspecto das imunidades tributárias previstas, a Constituição de 1967 e a Emenda Constitucional de 1969 retiraram a imunidade aos tributos do papel destinado à impressão de jornais, livros e periódicos.

Finalmente, a Constituição de 1988, em seu artigo 150, VI, "a" a “d”, e $\S \S 2^{\circ}$ a $4^{\circ}$, traz novos sujeitos imunes e conteúdos que aprimoram a compreensão das imunidades tributárias. Verifica-se que a Constituição vigente tornou-se mais detalhada, com uma nítida preocupação com as normas imunizantes.

\section{CONSIDERAÇÕES FINAIS}

Os Templos de Qualquer Culto, chamados pelo Código Civil de 2002 de organizações religiosas (inciso IV do artigo 44 da Lei 10.406/2002), executam diversas atividades sob o fundamento da liberdade de crença, da liberdade de divulgação das crenças e da liberdade de culto. Tais liberdades se justificam na medida em que sua supressão causaria uma violação ao direito de liberdade religiosa, em nível individual e coletivo.

As organizações religiosas, portanto, são titulares de direitos fundamentais, entre os quais, destacamos o direito à imunidade tributária. Todavia, a garantia do exercício da liberdade religiosa por essas organizações decorre da necessária sustentação da liberdade religiosa individual. A liberdade religiosa coletiva serve de atualização da liberdade pessoal (Machado, 1996, p. 235).

Daí porque as organizações religiosas são, na atual conjuntura, atores religiosos, políticos e sociais independentes, irredutíveis a grupo de indivíduos. Portanto, respondem na medida de seus atos coletivos, não sendo possível atribuir tal responsabilidade a seus membros individualmente considerados.

A questão torna-se ainda mais complexa quando estamos diante de atividades intrinsecamente associadas às finalidades religiosas, cuja rea- 
lização adquire relevo econômico. É o caso, por exemplo, da concessão de canais televisivos para igrejas ou comunidades religiosas, da comercialização da produção audiovisual, da alienação de ou aquisição de bens e serviços, do uso de recursos e financiamentos públicos.

Chama a atenção o caso das comunidades evangélicas pentecostais, que no Brasil e na América Latina possibilitaram a acumulação privada de capital por meio de suas organizações religiosas. Isso porque o apelo espiritual e as práticas proselitistas dessas confissões religiosas tiveram um impacto maior entre os indivíduos de menor poder aquisitivo, moradores de periferia de grandes cidades, menos assistidos por programas assistenciais, cuja migração para essas organizações religiosas desestabilizou a maioria numérica de católicos ${ }^{2}$.

A maior ligação entre o espírito empresarial e a organização religiosa propiciou a adoção de novas práticas, tais como estratégias de compra de emissoras de televisão e de rádio, a adesão de sistemas de franquia, uma ligação entre a política e as igrejas.

As novas crenças emergentes no Brasil estariam prosperando em uma fase de descrença quanto à possibilidade de ascensão individual e profis- sional. As novas igrejas pentecostais estariam ocupando o lugar do Estado na cobrança de impostos (dízimos e outras contribuições) e na oferta de serviços e redes de proteção social (Neri, 2011, p. 45-6).

$\mathrm{Na}$ medida em que tais organizações religiosas arrecadam mais, e melhor distribuem seus dividendos entre seus seguidores, através de práticas assistencialistas, acabam por ocupar um espaço que deveria ser público e laico. A mesma crítica, entretanto, deve também ser dirigida às doutrinas religiosas predominantes no cenário brasileiro. A própria Igreja Católica, antes majoritária entre as confissões religiosas, tem renovado suas práticas e atividades a fim de recuperar o espaço perdido para outras doutrinas abrangentes.

O que estamos defendendo é que o direito de liberdade religiosa não pode chegar ao ponto de abranger todos os aspectos do desenvolvimento dessas atividades. A natureza comercial de tais atividades deve balizar uma atuação estatal, em termos normativos do direito comum, como qualquer outro sujeito de direitos, sem que tal intervenção seja atacada como violação do direito de liberdade de crença. Desse modo, se evitaria a utilização abusiva e simulada da figura da liberdade

2 Ver NERI, Marcelo Cortês. Novo mapa das religiões. Rio de Janeiro: FGV, CPS, 2011. Disponível em: www.fgv.br/cps/religiao. 
religiosa, bem como a discriminação contra indivíduos e entidades não religiosas.

Sabe-se que o atual posicionamento do Supremo Tribunal Federal vai no sentido contrário. É dizer, para esta corte, que a imunidade tributária deve abranger não somente os prédios destinados ao culto religioso, mas também o patrimônio, a renda e os serviços relacionados com a finalidade essencial da entidade religiosa.

A doutrina tem-se manifestado no sentido de que a imunidade de templos de quaisquer cultos se restringem às atividades que estão direta e objetivamente relacionadas às finalidades das organizações religiosas (Carrazza, 2004, p. 689; Costa, 2006, p. 60; Paulsen, 2005, p. 303).

Ao Estado, portanto, não cabe estimular ou promover qualquer confissão ou prática religiosa, uma vez que é a razão pública o principio norteador da normatividade e da atuação pública em um Estado Democrático de Direito.

O Estado brasileiro, ao alargar as hipóteses de imunidades tributárias para diferentes práticas comerciais realizadas por organizações religiosas, afasta-se da racionalidade pública e viola o princípio da igual liberdade e igual dignidade de seus cidadãos, uma vez que privilegia atividades comerciais de organizações religiosas em detrimento das mesmas atividades desenvolvidas por sujeitos não religiosos, provocando distorções no mercado e situações de concorrência desleal.

Do ponto de vista da justiça fiscal, quando o Estado não é suficientemente eficaz em sua política tributária, no sentido de que seus instrumentos (normativos e institucionais) fiscais não são eficazes na promoção e garantia da igual liberdade e igual dignidade de todos os seus cidadãos, então, há que (re)pensar a que $(\mathrm{m})$ serve o direito de liberdade religiosa.

A manutenção das imunidades tributárias às organizações religiosas, no cenário brasileiro, não promove a efetividade do direito à liberdade religiosa. Ao contrário, se traduz em verdadeiro privilégio, em descompasso com a manutenção da esfera pública da liberdade e da igualdade.

\section{REFERÊNCIAS}

BALEEIRO, Aliomar; LIMA SOBRINHO, Barbosa. A Constituição de 1946. PORTO, Walter
Costa (coord.). Curso "Constituições do Brasil”. Brasília: Editora Escopo, 1987. 
BALTHAZAR, Ubaldo Cesar. História do Tributo no Brasil. Florianópolis: Fundação Boiteux, 2005. BLANCARTE, Roberto. O porquê de um Estado laico. In: LOREA, R. A. (Org.) Em defesa das Liberdades Laicas. Porto Alegre: Livraria do Advogado, 2008.

COSTA, Regina Helena. Imunidades Tributárias: Teoria e Análise da Jurisprudência do STF. 2. ed., revista e atualizada. São Paulo: Editora Malheiros, 2006.

DANELI FILHO, Eloi César; PILAN SOBRINHO, Liton. As constituições brasileiras e a imunidade tributária de templos de qualquer culto. Anais do XIX Encontro $\mathrm{Na}$ cional do CONPEDI, Fortaleza, Jun. 2010.

MARTINS, Ives Gandra da Silva. Curso de Direito Tributário, V. 1, 2. ed. Belém: CEJUP, 1993.

HABERMAS, Jurgen. Direito e Democracia: entre facticidade e validade. Rio de Janeiro: Tempo Brasileiro, 2003.

LOREA, Roberto Arriada. Cidadania Sexual e Laicidade: um estudo sobre a influência religiosa no Poder Judiciário. Tese de Doutorado. Programa de Pós-Graduação em Antropologia Social. Porto Alegre: UFRGS, 2008.
MACHADO, Jonatas Eduardo Mendes. Liberdade religiosa numa comunidade constitucional inclusiva: dos direitos da verdade aos direitos dos cidadãos. Boletim da Faculdade de Direito. Universidade de Coimbra: Coimbra Editora, 1996.

MARTON, R. Templos Religiosos: a imunidade do art. 150, VI, b, da Constituição Federal e o disposto pela mesma constituição no art. 195, §7º. Brasília: Biblioteca Digital da Câmara dos Deputados, dez. 2004.

NERI, Marcelo Cortês. Novo mapa das religiões. Rio de Janeiro: FGV, CPS, 2011.

PEREIRA, Gabriel Nunes. Imunidade Tributária de templos de qualquer culto e religiões brasileiras. Revista Brasileira de História das Religiões. Maringá, V. III, n. 9, $\mathrm{jan} / 2011$.

RAWLS, John. O Liberalismo politico. São Paulo: Ática, 2000.

SABBAG. Eduardo, Manual de direito tributário. São Paulo: Saraiva, 2009.

TEPEDINO, Gustavo. Aspectos polêmicos do tratamento fiscal conferido aos templos e às entidades de fins religiosos. Revista da Procuradoria-Geral da República, n. 5,1994 . 